The statistical methods we have used are extremely simple, and in most instances we have attempted to compare groups showing a single difference. While this approach could lead to oversimplification or distortion of results, an alternative method (Birch, 1964) allows more than one factor to be considered at a time, and the results obtained are substantially the same as our own.

\section{TablB VI.-Effect of Pre-eclamptic Toxaemia on Tissue Culture Response of Amnion}

\begin{tabular}{|c|c|c|c|c|c|c|c|c|}
\hline & \multicolumn{3}{|c|}{$\begin{array}{c}\text { “Normal" Women } \\
\text { Delivering at } \\
\text { 37-38 Weeks' } \\
\text { Gestation } \\
\end{array}$} & \multicolumn{3}{|c|}{$\begin{array}{c}\text { Pre-eclamptic } \\
\text { Women Delivering } \\
\text { at } 37-38 \text { Weeks' } \\
\text { Gestation }\end{array}$} & \multirow{3}{*}{$\begin{array}{l}\text { Differ- } \\
\text { ence in } \\
\text { Percen-. } \\
\text { tages }\end{array}$} & \multirow{3}{*}{$\begin{array}{l}\text { S.E. } \\
\text { of } \\
\text { Differ- } \\
\text { ence }\end{array}$} \\
\hline & \multirow{2}{*}{$\begin{array}{l}\text { No. } \\
\text { Tested }\end{array}$} & \multicolumn{2}{|c|}{ Growing } & \multirow{2}{*}{$\begin{array}{l}\text { No. } \\
\text { Tested }\end{array}$} & \multicolumn{2}{|c|}{ Growing } & & \\
\hline & & No. & $\%$ & & No. & $\%$ & & \\
\hline $\begin{array}{l}\text { Vaginal delivery } \\
\text { Caesarean section }\end{array}$ & $\begin{array}{l}15 \\
30\end{array}$ & $\begin{array}{r}9 \\
25\end{array}$ & $\begin{array}{l}60 \\
83 \cdot 3\end{array}$ & $\begin{array}{l}7 \\
8\end{array}$ & $\begin{array}{l}6 \\
8\end{array}$ & $\begin{array}{l}85 \cdot 7 \\
100\end{array}$ & $\begin{array}{l}25 \cdot 7 \\
16 \cdot 7\end{array}$ & $\begin{array}{l}18 \cdot 3 \\
7 \cdot 664\end{array}$ \\
\hline Total & 45 & 34 & $75 \cdot 5$ & 15 & 14 & $93 \cdot 3$ & $17 \cdot 8$ & 9.099 \\
\hline
\end{tabular}

\section{Conclusion}

In conclusion, this study is of value to virologists using amnion tissue culture in their work, since it points to means of improving culture results but going considerably beyond Duncan and Bell's speculations. From the clinical point of view, the scale of this study is too limited to permit any firm conclusions to be drawn, but seems to us to merit further, confirmatory work. The most interesting observations emerging at this stage are: (1) Although amnion is a foetal tissue, its behaviour in tissue culture is unrelated to intrauterine foetal growth and development. (2) The viability of amnion in culture declines as pregnancy progresses, but, independent of length of gestation, appears to be influenced by as yet unidentified biological changes mediating the onset of labour. Substantiation of this observation may lead to the elucidation of the nature of these changes.

\section{Summary}

Clinical data pertaining to mother and baby are correlated with the growth of human amnion in tissue culture.

Behaviour of amnion in culture is not related to intrauterine foetal growth and development.

It is shown that viability of amnion in culture declines as pregnancy progresses, but especially after the occurrence of labour, irrespective of its duration, and whatever the length of gestation.

Amnion from cases of pre-eclampsia has an enhanced success rate in tissue culture.

While the scale of this study precludes firm conclusions, it provides evidence that human amnion is sensitive to certain biological processes operative in pregnancy. If this can be confirmed some light may be shed on the actual nature of such processes.

The findings of this study are of interest to virologists using human amnion and anxious to improve the success rate of their tissue cultures.

We thank the consultant staff of Liverpool Maternity Hospital for access to women under their care, and are greatly indebted to Miss E. M. Davies, Superintendent of the Labour Ward, and her staff for their unfailing help, which made this study possible. Grateful acknowledgment is made of the help and advice given by Professor T. N. A. Jeffcoate and Professor P. E. Polani. We are also indebted to Mr. M. C. K. Tweedie and Mr. M. W. Birch for advice on the statistical treatment of the data, and to Mrs. Joan Morris and Mrs. Sylvia Lush for technical assistance.

\section{REFERENCES}

Birch, M. W. (1964). F. roy, statist. Soc. B, 26, 322.

Bourne, G. L. (1962a). The Human Amnion and Chorion, p. 117. Lloyd-Luke, London.

(1962b). Ibid., p. 185.

Duncan, I. B. R., and Bell, Eleanor, J. (1961). Brit. med. F., 2, 863.

Ferguson, J., and Tobin, J. O'H. (1958). Ibid., 1, 144.

Lahelle, O. (1956). Acta path. microbiol. scand., 39, 338.

Zitcer, E. M., Fogh, J., and Dunnebacke, T. H. (1955). Science, 122, 30 .

\title{
Herpes Simplex Lesions of Face Treated with Idoxuridine Applied by Spray Gun: Results of a Double-blind Controlled Trial
}

\author{
B. E. JUEL-JENSEN,* M.A., B.M., CAND.MED.; F. O. MACCALLUM, † M.A., M.D., B.SC., M.R.C.P.
}

Brit. med. F., 1965, 1, 901-903

In a double-blind controlled trial using $0.5 \%$ idoxuridine (I.D.U.) and placebo ointment (Juel-Jensen and MacCallum, 1964), we were unable to show any therapeutic advantage from the use of the active cream when applied to herpetic lesions of the skin. Burnett and Katz (1963) had reached similar conclusions. We suggested that this might be due to failure to get an adequate amount of the relatively insoluble substance into the affected cells, in vivo, although I.D.U. is active against herpes in vitro and in rabbit cornea. It occurred to us that it might be possible to get enough solution into close contact with the intracellular virus by spraying a fine mist of the I.D.U. solution into the skin under pressure. With a modified airgun for intradermal injections $0.1 \%$ I.D.U. solution was applied to five patients with herpes of the face. A marked \footnotetext{
* Hospital Medical Officer, Radcliffe Infirmary, Oxford; M.O., Univer-

t Consultant Virologist, Radcliffe Infirmary, Oxford ; University Lecturer
}

clinical improvement and an apparent shortening of the duration of the lesion occurred. As the apparent advantage might be due to a purely mechanical effect, we have carried out a double-blind controlled trial to compare the effect of $0.1 \%$ solution of I.D.U. in saline with that of normal saline.

\section{Methods}

Airgun for Intradermal Injection.-A " Mark 2 " Dermojet gun was used throughout. The gun consists of a detachable nozzle, and a glass reservoir which can be removed from the main instrument by unscrewing the head. The fluid to be injected is filled into the glass reservoir after the dismantled instrument has been sterilized by boiling or autoclaving. The reservoir is pushed home and the head screwed securely on to the main instrument. A lever on the side of the barrel com- 
presses air by operating a piston in a small cylinder. The air is released by pressing the button on top of the instrument, and a spray of the fluid is ejected (once) at high speed from the nozzle.

Experiments with Berlin blue on cadavers showed that if the instrument was used with the nozzle applied to the skin a deeply penetrating narrow jet of fluid was produced which might perforate from 5 to $7 \mathrm{~cm}$., depending on the toughness of the skin. There was comparatively little scatter. By holding the nozzle away from the skin a more widely scattered but less penetrating spray was obtained. In order to be able to hold the instrument at a fixed distance from the skin we had simple guards made which could be fixed on the head of the instrument. This gave a predictable area of scatter and depth of penetration $(0.5-1 \mathrm{~cm}$.) in loose tissue, with a $20-\mathrm{mm}$. guard which was used throughout.

One to four shots were used, depending on the extent of the lesion, but not more than one application was given to any single area. Each discharge releases about $0.1 \mathrm{ml}$. of fluid. A small entry wound is produced which scabs over and heals like an ordinary pinprick wound of the skin. We recorded two end-points: (1) the time the herpetic lesion took to disappear completely, leaving only the scab of the entry wound, and (2) the time elapsed before the scab had disappeared also. We noted the patients' comment on whether or not the unpleasant tingling and itching of the lesion had disappeared within an hour, as the initial group of patients had remarked on the surprisingly early disappearance of this symptom.

The patients in the trial were drawn from the medical students of the clinical school and from the staff of the Radcliffe Infirmary. Herpes sufferers reported as soon as possible and not later than 24 .hours after the onset of the first symptoms. A careful history was taken, including information about the duration of previous attacks. A swab from the lesion was taken into virus transport medium, and the sample was sent to the virus laboratory within an hour. The patient was treated once only as described above, and reported back daily until the lesion had gone.

Active $0.1 \%$ I.D.U. solution and normal saline had been put up in identical bijou bottles in random order. Each bottle was labelled with a number for subsequent identification, and contained enough material to fill the chamber of the gun once, leaving a residue for the virus laboratory for confirmatory tests. The contents of the bottle were unknown to the patient and the observer. The same observer saw each patient daily and recorded details of progress.

\section{Results}

Twenty patients participated (three developed a lesion in a new site after a clear interval and were entered again, making 23 patient attacks) and all completed the trial. Twelve received active I.D.U. solution, 11 saline. In four of these patients, two in each group (Nos. 3, 4, 5, and 18), the clinical diagnosis of herpes was certain, and antibodies to herpes were present, but we failed to isolate the virus. The results are set out in the Table.

In the whole group the average duration of the attack to apparently complete disappearance of the herpetic lesion, but leaving the scab of the entry wound, was 2.17 days (S.E. \pm 0.54 ) in the group on active treatment, and 4.09 days (S.E. \pm 0.71 ) in the group receiving placebo. The scabs had also gone after 5.50 day (S.E. +1.04 ) in the former and after 8.82 days (S.E. $\pm 1.28)$ in the latter group. If the herpes-negative patients are excluded the figures were only slightly altered: 2.40 (S.E. \pm 0.63 ) and 4.33 (S.E. \pm 0.73 ) to healing; 6.20 (S.E. \pm 1.13 ) and 8.89 (S.E. \pm 1.15 ) to disappearance of the entry scab. There was thus a shortening of the average duration of the attack to the point when the scab only was present of 1.92 days (47\%), and of 3.32 days (37\%) to complete healing in all patients (or $1.93(35 \%)$ and $2.69(30 \%)$ days in the herpes-positive group).

The technique and results of virology were as described in our previous paper.

Results of I.D.U. $0.1 \%$ Solution Given by Modified Dermojet Gun

\begin{tabular}{|c|c|c|c|c|c|c|}
\hline Patient & I.D.U. & $\begin{array}{c}\text { Usual } \\
\text { Duration } \\
\text { (Days) }\end{array}$ & $\begin{array}{c}\text { Scab } \\
\text { of Entry } \\
\text { Hole Only } \\
\text { (Days) }\end{array}$ & $\begin{array}{c}\text { Scab } \\
\text { Gone } \\
\text { (Days) }\end{array}$ & $\begin{array}{c}\text { Treatment } \\
\text { Started } \\
\text { (Hours) }\end{array}$ & $\begin{array}{c}\text { Tingling } \\
\text { Gone } \\
\text { Within } \\
\text { Hour } \\
\end{array}$ \\
\hline $\begin{array}{r}1 \\
2 \\
3 \\
4 \\
5 \\
6 \\
7 \\
8 \\
9 \\
10 \\
11 \\
12 \\
13 \\
14 \\
15 \\
16 \\
17 \\
18 \\
19 \\
20 \\
21 \\
22 \\
23\end{array}$ & $\begin{array}{l}\text { Active } \\
\text { Saline } \\
\text { Active } \\
\text { Saline } \\
\text { \# } \\
\text { Active } \\
\text { Saline } \\
\text { Active } \\
\text { "” } \\
\text { Saline } \\
\text { " } \\
\text { Active } \\
\text { Saline } \\
\text { Active } \\
\text { Saline } \\
\text { Active } \\
\text { " }\end{array}$ & $\begin{array}{c}7 \\
10-14 \\
14 \\
10-14 \\
14-21 \\
7 \\
5-7 \\
7 \\
10 \\
7 \\
7 \\
14 \\
7 \\
7-10 \\
7 \\
7 \\
7-21 \\
7-14 \\
14 \\
7 \\
13 \\
7 \\
14\end{array}$ & $\begin{array}{l}2 \\
5 \\
1 \\
5 \\
1 \\
7 \\
2 \\
2 \\
8 \\
2 \\
2 \\
6 \\
2 \\
4 \\
3 \\
1 \\
3 \\
1 \\
1 \\
1 \\
6 \\
6 \\
\frac{1}{2}\end{array}$ & $\begin{array}{r}9 \\
9 \\
2 \\
15 \\
2 \\
8 \\
7 \\
6 \\
9 \\
3 \\
7 \\
14 \\
10 \\
6 \\
9 \\
5 \\
7 \\
2 \\
2 \\
5 \\
17 \\
7 \\
1\end{array}$ & $\begin{array}{c}9 \\
6 \\
5 \\
5 \\
5 \\
12 \\
17 \\
17 \\
31 \\
6 \\
31 \\
2 \\
6 \\
6 \\
12 \\
31 \\
3 \\
7 \\
15 \\
8 \\
13 \\
13 \\
3 \frac{13}{3}\end{array}$ & $\begin{array}{l} \pm \\
\pm \\
\pm \\
\pm \\
\pm \\
\pm \\
\pm \\
\pm \\
\pm \\
\pm \\
\pm \\
+ \\
+ \\
+ \\
\pm \\
\pm \\
+\end{array}$ \\
\hline
\end{tabular}

\section{Discussion}

In our previous paper we failed to demonstrate any therapeutic advantage from the use of $0.5 \%$ I.D.U. over a placebo cream applied to the surface of herpetic lesions of the face in a double-blind controlled trial. We suggested that this failure of I.D.U. in vivo might well be due to a lack of intimate contact of the active agent with the affected cells. We also suggested that it might be possible to overcome this difficulty by spraying a fine mist of the I.D.U. solution into the skin. The results of the present trial show beyond any reasonable doubt that the antiviral substance I.D.U., which has proved effective in vitro, is active against herpes virus in the skin in man when applied as outlined above. It is possible that the mere mechanical insult of the treatment may help to hasten recovery, possibly by making it easier for circulating antibody to reach the affected tissue. (All patients in the group had titres of antibody proving previous attacks with herpes.) This may explain why the time it takes for the obvious herpetic lesion to heal, still leaving a scab of the entry hole of the jet, is shorter than the average of the patients' estimated duration of past similar lesions. On the other hand the first "end-point," the scab, may not represent the true finish of the herpetic lesion. For this there is some evidence: the time taken for complete healing, 8.82 days in the whole placebo group ( 8.89 days in the herpespositive group) is remarkably similar to the average time the lesions took to heal in our series of patients treated with I.D.U. cream and placebo cream: 8.9 days for those treated with active cream, 8.6 days for those treated with inactive cream. The patient's own estimate of the usual duration was only slightly longer than the observed average: 10.0 days in the whole group, 9.3 days in the herpes-positive group. Even if a possible advantage from the mechanical insult of the treatment is postulated, I.D.U. solution retains a clear advantage over saline.

It is of interest to look at the results for the three entrants who developed a lesion on more than one occasion. One (Nos. 15 and 16) shows a clear advantage from I.D.U., another (Nos. 2 and 4) received placebo on both occasions, and the result was much as he had predicted. The third patient entered three times (Nos. 13, 20, and 22). He derived no benefit from the active treatment. It will be seen from this that these patients 
relapsed after an interval, but none to date have had a lesion in the same site, although they stated that this had always occurred previously. It remains to be seen to what extent the treatment is curative when it has been applied. Failure in method (inadequate cover of the whole affected area) may explain why some patients derived little benefit from the treatment, or the virus may have been I.D.U.-resistant. All strains isolated are being examined for this property. All lesions occurred on the face round the mouth, on the lips, and in one instance on the nose.

The unusual form of treatment presented no major practical problems in the group investigated. The patients feel a sharp impact, and may ooze a little blood from the entry wound for a minute or two. On the other hand many expressed delight with the (as it turned out) real shortening of the attack, and commented on the rapidity with which the unpleasant itching and tingling went, often within an hour. This seems to be a real advantage in the group treated with I.D.U. (10 of 12 in the active, 3 of 11 in the placebo group). We have since used the spray gun in the treatment of herpetic paronychia, and have found that the duration of the lesions was apparently shortened, that the virus disappeared or became very scanty after treatment, and that the patient experienced relief from the often excruciating pain in this condition.

\section{Summary}

Twenty-three patients with herpes of the face participated in a double-blind controlled trial to test the effect of 5-iodo-2'deoxyuridine (idoxuridine), $0.1 \%$ in aqueous solution. The solution was applied with a modified airgun for intradermal injection. In 12 patients receiving the active I.D.U. solution in a single treatment there was an average shortening of the duration of the lesion of 3.32 days (or $37 \%$ ) compared with the average duration (8.87 days) in 11 receiving saline. A true therapeutic effect of I.D.U. on herpes infections of the skin has been demonstrated.

Our thanks are due to Dr. T. A. Turnbull, of Smith Kline and French Laboratories Ltd., for the supply of I.D.U., and for a Dermojet "Mark 2 " airgun ; to Mr. B. A. Stone, of the workshop of the Regius Professor of Medicine's Department, for machining guards to our design; to Mr. Ivor Ohinn for his help with the virus cultures; and, not least, to our long-suffering patientsdoctors, medical students, nurses, and other members of the hospital staff-for their intelligent co-operation.

\section{REFERENCES} Burnett, J. W., and Katz, S. I. (1963). f. invest. Derm., 40, $7 . \dot{\text {. }}$
Juel-Jensen, B. E., and MacCallum, F. O. (1964). Brit. med. 987.

\title{
Outbreak of Dysentery Due to Contact with a Pet Monkey
}

\author{
D. T. ROBINSON,* M.SC., M.R.C.S., L.R.C.P., DIP.BACT., F.C.PATH. ; \\ ELIZABETH C. ARMSTRONG, $\dagger$ M.D., DIP.BACT., M.C.PATH. ; \\ K. PATRICIA CARPENTER, $\ddagger$ M.B., CH.B., DIP.BACT., M.C.PATH.
}

Brit. med. F., 1965, 1, 903-905

Apart from man, the simian primates are the only animals to suffer naturally from bacillary dysentery caused by organisms of the Shigella genus. Shigella infections in these animals have been well known to those in charge of monkey colonies since the early days of bacteriology (Grunbaum, 1904 ; Ravaut and Dopter, 1909), but with the importation of large numbers of primates for laboratory use in recent years the possible hazards of these and other natural infections of monkeys to human contacts have become more widespread. Though bacillary dysentery in humans is undoubtedly a much less serious disease than the rare but fatal infection caused by the monkey $B$ virus, Herpesvirus simiae, which may follow a monkey-bite or scratch, the incidence of shigella infections in imported monkeys is sufficiently high to constitute a potential risk. Ruch (1959) comprehensively reviewed both the published and unpublished records of the spread of bacillary dysentery from monkeys to human contacts, and, though the number of such incidents is small, fatalities have occurred (Bach et al., 1931).

Laboratory workers and curators of primate colonies are aware of these hazards, but outside such circles the risks of human association with monkeys are not widely known, and there is some evidence that increasing numbers of monkeys are being bought as household pets by the public. These pets, whether bought in this country from pet stores or brought in from abroad by returning travellers, are not subject to any quarantine regulations and probably only very few are inspected

\footnotetext{
* Director, Public Health Laboratory, Liverpool ; Associate Professor of Bacteriology, University of Liverpool.

t Senior Bacteriologist, Public Health Laboratory, Liverpool.

‡ Director, Dysentery Reference Laboratory, Colindale, London.
}

by a veterinary surgeon. Children, being particularly susceptible to shigella infections, are at special risk from monkey pets. Carpenter and Sandiford (1952) drew attention to this point, and in a memorandum prepared by the British Veterinary Association Exotic Animals Subcommittee Appleby et al. (1963) likewise recommended the collaboration of veterinary surgeons and medical practitioners in advising and educating the public about monkey pets. The outbreak described here well illustrates the unsuitability of a monkey as a domestic pet.

\section{Index Case}

The index case, D. H., was a girl aged 2 years who developed severe diarrhoea on 15 February 1963 and was admitted to hospital next day. The child apparently mentioned to the ward sister that her uncle had brought home a pet monkey. From the specimen of the child's faeces a strain of Shigella flexneri was isolated and the local medical officer of health was notified accordingly. The strain was subsequently identified as $S h$. flexneri $\mathrm{Y}$ and had the epidemiologically useful marker of being catalase-negative, a rare finding in Sh. flexneri (Carpenter and Lachowicz, 1959). The records at the Dysentery Reference Laboratory show that Sh. flexneri $\mathrm{Y}$ is more often encountered in primates than in human beings, so it was very suggestive that the monkey was implicated in the child's disease. The epidemiological investigation which followed reyealed an interesting story, told now for clarity in chronological order. Details of the families and cases involved are given in Table I. 